\title{
Aberrant p16INK4A methylation: Relation to viral related chronic liver disease and hepatocellular carcinoma
}

\author{
Fatma A. El-Mougy, Mohammed M.Youssef', Dalia A. Omran', Sahar A. Sharaf, Hany H. El-Sayed, Walaa A. Rabie,
} Elghobary A. Mohamed², Hany A. Elghobary

\begin{abstract}
Background: Hepatocellular carcinoma (HCC) is currently the fifth most common solid tumor worldwide and the third leading cause of cancer related deaths. Several studies have shown that the tumor suppressor gene pI6INK4A is frequently downregulated by aberrant methylation of the 5'-cytosine-phosphoguanine island within the promoter region. Aim: To find out the frequency of methylated pI6INK4A in the peripheral blood of HCC and cirrhotic patients and to evaluate its role in hepatocarcinogenesis. Patients and Methods: This study was performed on 58 subjects: $30 \mathrm{HCC}$ patients, 20 cirrhotic patients, and eight healthy volunteers. Methylation of p I6INK4A was examined using methylation specific polymerase chain reaction (PCR) (MSP). Comparison of quantitative variables between the study groups was done using Mann-Whitney $U$ test for independent samples when not normally distributed. For comparing categorical data, Chi-square $\left(\chi^{2}\right)$ test was performed. Exact test was used instead when the expected frequency was less than 5. Results: Methylation of pI6INK4A was found in $6.7 \%$ of HCC patients, $5 \%$ of liver cirrhosis (LC) patients, and none of the healthy volunteers; $66.67 \%$ of the pI6INK4A-methylated cases (2/3) were positive for anti-hepatitis $C$ virus $(\mathrm{HCV}$ ) antibodies (one of them had $\mathrm{HCC}$ ). All HCC cases with aberrant pI6INK4A methylation show very high serum alpha fetoprotein (AFP) level $(9,080 ; 30,000 \mu \mathrm{g} / \mathrm{mL})$. There were no significant associations between the status of p I 6INK4A methylation and tumor size. Conclusion: Hypermethylation of pI6INK4A was found to be infrequent among Egyptian patients with HCC.
\end{abstract}

Key words: Hepatocellular carcinoma, methylation, pI6INK4A

\section{Introduction}

Hepatocellular carcinoma (HCC) is the fifth most common and the third most fatal malignancy worldwide. ${ }^{[1]}$ The burden of HCC has been increasing in Egypt, with a doubling in the incidence rate in the past 10 years. ${ }^{[2]}$

Inactivation of tumor suppressor genes and activation of oncogenes initiated by genetic and epigenetic changes may play an important role in carcinogenesis. ${ }^{[3]}$ The p16INK4A gene is a tumor suppressor, located on chromosome 9p21 and encodes the p16 protein, which binds selectively to CDK4 to inhibit activation of the cyclin-dependent kinase 4 (CDK4)/ cyclin D complex in the G1phase of the cell cycle. ${ }^{[4]}$

Reduced expression of the p16INK4A gene results in uncontrolled division of cells. Several mechanisms that lead to p16INK4A inactivation had been described, including point mutations, homozygous deletions, and promoter hypermethylation. ${ }^{[5]}$ Aberrant methylation of the p16INK4A promoter has also been reported in early preneoplastic

Departments of Clinical and Chemical Pathology, 'Endemic Medicine and Hepatology, ${ }^{2}$ Internal Medicine, Faculty of Medicine, Cairo University, Cairo, Egypt

Correspondence to: Dr. Dalia Omran,

E-mail: daliaomran2007@yahoo.com

\begin{tabular}{|l|l|}
\hline \multicolumn{2}{|c|}{ Access this article online } \\
\hline Quick Response Code: & Website: \\
\hline & www.sajc.org \\
\hline & \\
\hline
\end{tabular}

lesions in the lung, colon, esophagus, and pancreas. These findings suggest that loss of p16INK4A function, often due to promoter methylation, may be an early event in the pathogenesis of various types of tumors. ${ }^{[6]}$ However, reports on p16INK4A methylation in $\mathrm{HCC}$ were remarkably diverse. ${ }^{[7]}$ The present study was performed to estimate the frequency of methylated p16INK4A in the peripheral blood of patients with liver cirrhosis (LC) and HCC to evaluate its role in hepatocarcinogenesis.

\section{Materials and Methods}

This study included 30 patients with HCC and 20 patients with cirrhosis. Cirrhosis patients were diagnosed on the basis of clinical, biochemical, ultrasound findings, and transient elastography value of $>14.5 \mathrm{kPa}$ (cutoff value for diagnosis of stage 4 fibrosis). HCC patients were diagnosed according to the criteria of the European Association for the Study of the Liver (EASL). ${ }^{[8]}$ Eight healthy age and sex matched volunteers were included as controls. After obtaining an approval from the institutional ethical committee, and an informed consent signed by every involved subject according to the Declaration of Helsinki, blood samples were collected prospectively and were subjected to testing of anti-hepatitis $\mathrm{C}$ virus (HCV) antibodies using second generation enzyme-linked immunosorbent assay (ELISA; Boehringer Mannheim Immunodiagnostics for ES-300). Hepatitis B surface antigen (HBsAg) and hepatitis B core antibodies (HB core $\mathrm{Ab}$ ) total were tested by ELISA test (ELISA-Abbot Laboratories), alpha fetoprotein (AFP) level was tested using automated analyzer Immulite 2000 (kits supplied by Siemens Diagnostics). Determination of p16INK4A methylation status was done using methylation specific polymerase chain reaction (PCR) (MSP). 
Genomic DNA extraction from ethylenediaminetetraacetic acid (EDTA) anticoagulated whole blood was done using DNA extraction minikit (QIAamp; DNA Blood Mini Kits-50; Catalog no. 51104, Qiagen: www.qiagen.com). The methylation status of a DNA sequence can best be determined using sodium bisulfite. Incubation of the target deoxyribonucleic acid (DNA) with sodium bisulfite results in conversion of unmethylated cytosine residues into uracil, leaving the methylated cytosines unchanged. ${ }^{[9]}$

Bisulfite modification of extracted DNA was done using EpiTect Bisulfite Kit (catalog no. 59104; QIAGEN epigenomics).

PCR amplification: Enzymatic amplification using Taq polymerase enzyme and the PCR master mix (Fermentas Life Sciences; Catalog No. K0171; Fermentas UAB V. Graiciuno 8, LT-02241 Vilnius, Lithuania.), this was done on the Hybaid thermal cycler (Promega Corporation, USA). Two sets of primers specific for the methylated p16INK4A sequence were used (product size, $150 \mathrm{bp}$ ). ${ }^{[10]}$ Sense: 5'-TTATTAGAGGGTGGGGCGGATCGC-3', antisense: 5'-GACCCCGAACCGCGACCGTAA-3'.

Quality control of the bisulfite conversion process was used, all bisulfite-treated DNA was also amplified using primers specific for the unmethylated p16 sequence (product size, 151 bp). ${ }^{[10]}$ Sense: 5'-TTATTAGAGGGTGGGGTGGATTGT-3', antisense: 5'CAACCCCAAACCACAACCATAA-3'.

The thermal profile consisted of: An initial denaturation step of $95^{\circ} \mathrm{C}$ for $12 \mathrm{~min}$ followed by repetitions of $95^{\circ} \mathrm{C}$ for $45 \mathrm{~s}, 60^{\circ} \mathrm{C}$ for methylated, and $56^{\circ} \mathrm{C}$ for the unmethylated primer for $45 \mathrm{~s}$ and $72^{\circ} \mathrm{C}$ for $60 \mathrm{~s}$, with a final extension step of $72^{\circ} \mathrm{C}$ for $10 \mathrm{~min} .{ }^{[11]}$ The PCR amplification products were then run in parallel on $1.5 \%$ agarose gel electrophoresis and visualized on a ultraviolet (UV) transilluminator to detect the specific band, only methylated DNA samples should give bands for methylated p16INK4A between 100 and $200 \mathrm{bp}^{[12]}$ as shown in Figures 1 and 2. All samples should give bands for unmethylated p16INK4A indicating efficient bisulfite conversion as shown in Figure 3.

\section{Statistical methods}

Data were statistically described in terms of range, mean $\pm \mathrm{SD}$ (standard deviation), frequencies (number of cases), and relative frequencies (percentages) when appropriate. Comparison of quantitative variables between the study groups was done using Mann-Whitney $U$ test for independent samples when not normally distributed. For comparing categorical data, Chi-square $\left(\chi^{2}\right)$ test was performed. Exact test was used instead when the expected frequency was less than 5 . A probability value ( $P$ value) less than 0.05 was considered statistically significant. All statistical calculations were done using computer programs Microsoft Excel 2003 (Microsoft Corporation, NY and USA) and Statistical Package for the Social Science (SPSS; SPSS Inc., Chicago, IL, USA) version 15 for Microsoft Windows.

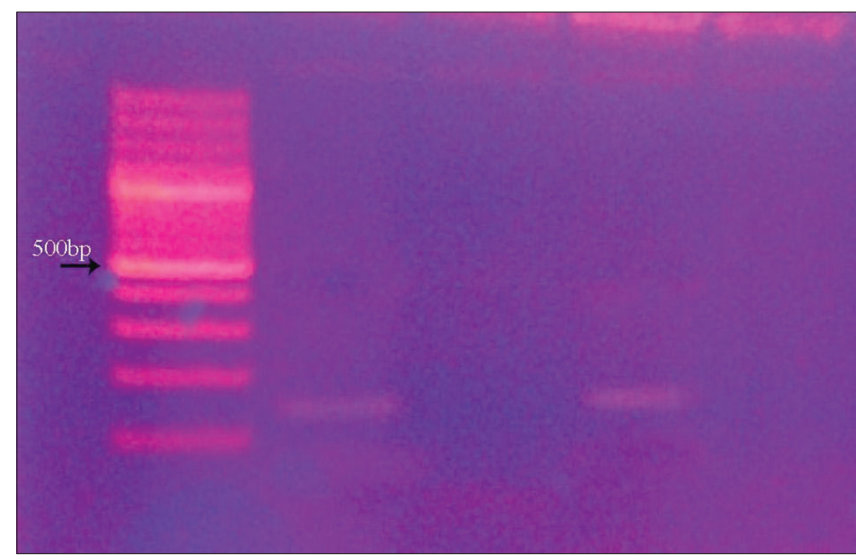

Figure 1: Detection of products of methylation specific polymerase chain reaction (MSP) for aberrant p16INK4A methylation. Lane 1:100 bp ladder. Lanes 2, 4: Bands for methylated p16INK4A in hepatocellular carcinoma cases between 100 and 200 bp

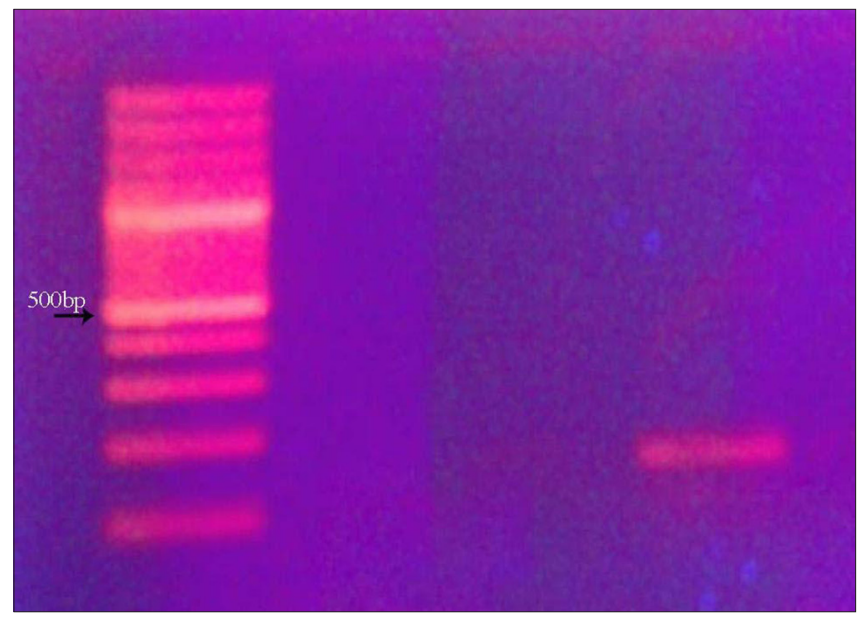

Figure 2: Detection of products of MSP for aberrant p16INK4A methylation. Lane 1: 100 bp ladder. Lane 4: Band for methylated p16INK4A in liver cirrhosis cases between 100 and 200 bp

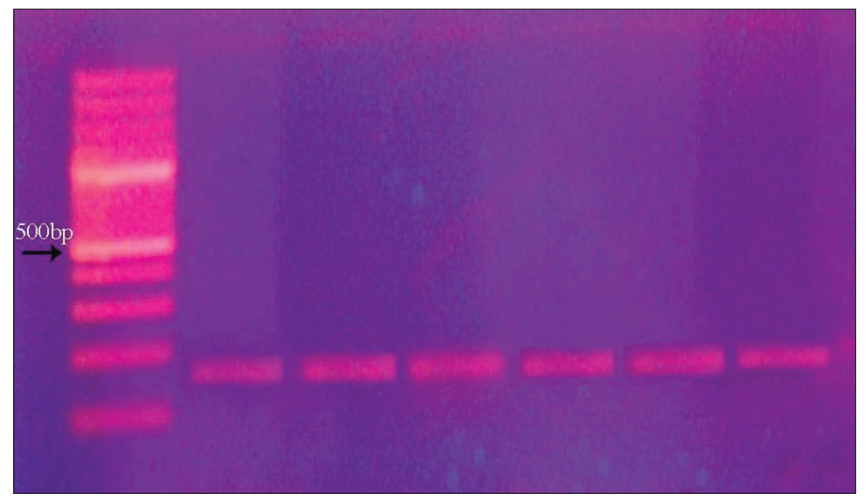

Figure 3: Detection of products of the unmethylated (quality control) primer. Lane 1: $100 \mathrm{bp}$ ladder, lanes 2-7: Bands for unmethylated p16INK4A between 100 and 200 bp

\section{Results}

Of the 58 patients included in the analysis, $66.7 \%$ patients were males. The demographic, clinical, and laboratory data of the studied patients are shown in [Table 1].

Serum AFP median level was 114 (40-407) $\mu \mathrm{g} / \mathrm{L}$ in the patients with $\mathrm{HCC}, 3.8(2.5-7.7) \mu \mathrm{g} / \mathrm{L}$ in patients with $\mathrm{LC}$, 
Table 1: Clinical and laboratory features of cirrhosis and $\mathrm{HCC}$ patients

\begin{tabular}{lccc}
\hline Variables & $\begin{array}{c}\text { HCC } \\
(n=30)\end{array}$ & $\begin{array}{c}\text { Cirrhosis } \\
(\boldsymbol{n}=\mathbf{2 0})\end{array}$ & $P$ value \\
\hline $\begin{array}{l}\text { Age (years), } \\
\text { mean } \pm \text { SD }\end{array}$ & $57.6 \pm 8.8$ & $49.2 \pm 9.3$ & 0.002 \\
$\begin{array}{l}\text { Sex }(\mathrm{M} / \mathrm{F}) \\
\text { Etiology (\%) } \\
\quad \text { Chronic } \\
\text { hepatitis B }\end{array}$ & $20 / 10$ & $14 / 6$ & 0.4 \\
$\begin{array}{l}\text { Chronic } \\
\text { hepatitis C }\end{array}$ & $23 / 30(13.3 \%)$ & $2 / 20(10 \%)$ & 0.6 \\
$\quad \begin{array}{l}\text { Combined B } \\
\text { and C }\end{array}$ & 0 & $14 / 20(70 \%)$ & 0.7 \\
$\begin{array}{l}\text { Alpha fetoprotein } \\
(\mu \mathrm{g} / \mathrm{L}) \text { (median }\end{array}$ & $114(40-407)$ & $3.8(2.5-7.7)$ & $0.001 *$ \\
and range) & & & \\
\hline *Significant $P \leq 0.05$. HCC: Hepatocellular carcinoma, M: Male, F: Female, \\
SD: Standard deviation
\end{tabular}

and $2.25(1.32-2.95) \mu \mathrm{g} / \mathrm{L}$ in normal controls. Receiver operating characteristic curves were plotted and showed an optimal cutoff value for AFP; being $27.95 \mu \mathrm{g} / \mathrm{mL}$ with sensitivity of $86.2 \%$ and specificity of $100 \%$ when the area under the receiver operator characteristic (AUROC) curve was 0.95 [Figure 4].

Methylated p16INK4A was detected in $6.7 \%(2 / 30)$ of HCC patients, $5 \%(1 / 20)$ of LC patients, and none of the healthy volunteers.

There were no significant associations between the status of p16INK4A methylation and tumor size [Table 2]. Aberrant p16INK4A methylation was significantly associated with high level of serum AFP $(9,080 ; 30,000 \mu \mathrm{g} / \mathrm{mL})$.

\section{Discussion}

The present study showed a male predominance among HCC patients (66.7\%). This could be explained by the fact that DNA synthetic activities are reportedly higher in male than in female cirrhotic tissue. ${ }^{[13]}$ Moreover, the high levels of 2-methoxyestradiol, an estrogen metabolite produced in the females' liver during their reproductive years has a protective effect against HCC. ${ }^{[14]}$

Chronic infection with hepatitis B virus (HBV) or HCV is a major risk factor for $\mathrm{HCC}$ worldwide; in the present study, we showed that aberrant p16INK4A methylation status was related to chronic HBV and $\mathrm{HCV}$ infection. Kaneto et al. ${ }^{[15]}$ reported that p16INK4A methylation was detected in virus associated chronic hepatitis and cirrhosis, but not in normal liver. These observations suggest that a chronic viral hepatitis may play a role in the induction of p16INK4A promoter methylation in hepatocarcinogenesis, possibly starting at an early stage.

Li et al., ${ }^{[16]}$ reported that HCCs with p16INK4A methylation were only found in individuals with HBV or $\mathrm{HCV}$ infection and not in virus negative individuals.

Jung et al., ${ }^{[17]}$ reported that HBV X protein induced DNA hypermethylation of the p16INK4A gene promoter to
Table 2: Association between p16INK4A methylation and tumor size in patients with hepatocellular carcinoma

\begin{tabular}{lccc}
\hline & $\begin{array}{c}\text { p16INK4A } \\
\text { positive } \\
\text { methylation }\end{array}$ & $\begin{array}{c}\text { p16INK4A } \\
\text { negative } \\
\text { methylation }\end{array}$ & $P$ value \\
\hline $\begin{array}{c}\text { Tumor size } \\
\leq 3 \mathrm{~cm}(n=12)\end{array}$ & 0 & 12 & 0.2 \\
$3 \mathrm{~cm}(n=18)$ & 2 & 16 & \\
\hline
\end{tabular}

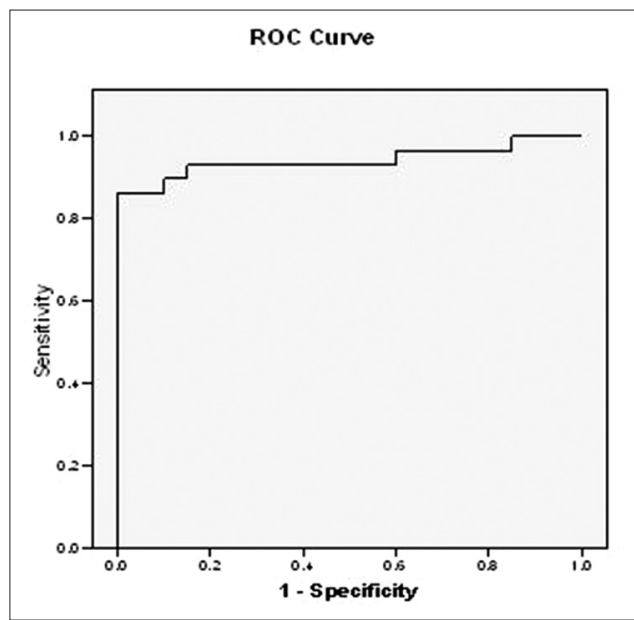

Figure 4: Receiver operating characteristic curve for alpha fetoprotein

repress its expression and led to transcriptional activation of DNA methyltransferase 1(DNMT1) via the cyclin D1-CDK4/6-pRb- E2F1 pathway, suggesting a close relationship between hepatitis virus infections and aberrant methylation of the p16INK4A gene.

Considering the different mechanisms that occur for HBV- and HCV-related hepatocarcinogenesis, ${ }^{[18]}$ it seems reasonable to hypothesize that the two viruses may have different effects on p16INK4A methylation. Another study had shown geographic variations in the methylation status of multiple genes involved in HCC. ${ }^{[19]}$ Weihrauch et al., ${ }^{[20]}$ had reported a higher frequency of p16INK4A hypermethylation in HCCs obtained from workers exposed to vinyl chloride, compared with nonexposed controls. These observations suggest that multiple risk factors exist, including exogenous factors, like viral infections and vinyl chloride exposure.

The reported rate of incidence of p16INK4A methylation in $\mathrm{HCC}$ is quite variable, ranging from 0 to $94 \%{ }^{[15,21,22]}$ and from 29.4 to $83 \%$ in cirrhosis. ${ }^{[15,21,23]}$ Wong et al., ${ }^{[24]}$ reported that p16INK4A methylation was neither detected in the plasma of patients with LC nor hepatitis. In the present study, abnormal p16INK4A methylation was detected in $6.7 \%(2 / 30)$ of HCC patients and in 5\% (1/20) of LC patients. Further studies on plasma or sera are required and more meticulous methods may be required to detect p16INK4A methylation in LC patients, as the amount of circulating DNA is lower in the sera of LC patients than in that of HCC patients. Moreover, using 
peripheral blood DNA actually means dilution of circulating methylated tumor DNA by nontumorous unmethylated DNA derived from peripheral blood leukocytes. So utilizing a more efficient kit for extraction of minimal amounts of segmented circulating DNA could be a key step to achieve a percent of DNA methylation closer to reality. Another explanation for the discrepancy between the results of this study and other studies could be the use of agarose gel electrophoresis which is less efficient than Southern blotting. Moreover, it is recommended to use the gold standard method for detection of methylation which is bisulfite conversion of DNA followed by sequencing.

The clinical significance of promoter hypermethylation in tumor progression involves the transcriptional repression of tumor suppressor genes, DNA repair genes, and metastasis inhibitor genes. ${ }^{[25]}$ So, detection of aberrant DNA methylation is very important for understanding the mechanisms of oncogenesis and may form basis for cancer diagnosis and monitoring. ${ }^{[26]}$

\section{Conclusion}

Our study showed that methylated p16INK4A was found infrequently among HCC patients in Egypt. Further research should focus on performing more studies on a larger sample size and to combine both tissue and blood samples, also extraction kits specially designed for viral DNA detection which could be more efficient in extraction of segmented circulating DNA.

\section{Acknowledgment}

We would like to thank Dr. Nabeel El Kady, Professor of Tropical Medicine, Cairo University for his contribution and continuous support throughout this work.

\section{References}

1. El-Serag HB, Rudolph. KL. Hepatocellular carcinoma: Epidemiology and molecular carcinogenesis. Gastroenterology 2007; 132:2557-76.

2. Anwar WA, Khaled HM, Amra HA, El-Nezami H, Loffredo CA. Changing pattern of hepatocellular carcinoma (HCC) and its risk factors in Egypt: Possibilities for prevention. Mutat Res 2008;659:176-84.

3. Shiraz OB, Galehdari H, Yavarian M, Geramizadeh B. Possible down regulation of the $p 16$ gene promoter in individuals with hepatocellular carcinoma. Hepat Mon 2011;11:719-23.

4. Thorgeirsson SS, Grisham JW. Molecular pathogenesis of human hepatocellular carcinoma. Nat Genet 2002;31:339-46.

5. Matsuda Y. Molecular mechanism underlying the functional loss of cyclindependent kinase inhibitors p16 and p27 in hepatocellular carcinoma. World J Gastroenterol 2008; 14:1734-40.

6. Merlo A, Herman JG, Mao L, Lee DJ, Gabrielson E, Burger PC, et al. 5 $\mathrm{CpG}$ island methylation is associated with transcriptional silencing of the tumour suppressor p16/CDKN2/MTS1 in human cancers. Nat Med 1995; 1:686-92.

7. Zang JJ, Xie F, Xu JF, Qin YY, Shen RX, Yang JM, et al. P16 gene hypermethylation and hepatocellular carcinoma: A systematic review and meta-analysis. World J Gastroenterol 2011;17:3043-8.

8. Bruix J, Sherman M, Llovet JM, Beaugrand M, Lencioni R, Burroughs AK, et al. Clinical management of hepatocellular carcinoma. Conclusions of the Barcelona-2000 EASL conference. European association for the study of the liver. J Hepatol 2001;35:421-30.
9. Clark SJ, Harrison J, Paul CL, Frommer M. High sensitivity mapping of methylated cytosines. Nucleic Acids Res 1994;22:2990-7.

10. Herman JG, Graff JR, Myohanen S, Nelkin BD, Baylin SB. Methylation-specific PCR. A novel PCR assay for methylation status of CpG islands. Proc Natl Acad Sci USA 1996;93:9821-6.

11. Song N, Tan W, Xing D, Lin D. CYP $1 A 1$ polymorphism and risk of lung cancer in relation to tobacco smoking: A case control study in china. Carcinogenesis 2001;22:11-6.

12. Wong IH, Zhang J, Lai PB, Lau WY, Lo YM. Quantitative analysis of tumor-derived methylated $\mathrm{p} 16 \mathrm{INK} 4 \mathrm{a}$ sequences in plasma, serum, and blood cells of hepatocellular carcinoma patients. Clin Cancer Res 2003;9: 1047-52.

13. Tarao K, Ohkawa S, Shimizu A, Harada M, Nakamura Y, Ito Y, et al. The male preponderance in incidence of hepatocellular carcinoma in cirrhotic patients may depend on the higher DNA synthetic activity of cirrhotic tissue in men. Cancer 1993;72:369-74.

14. Lui WY, Lin HL, Chau GY, Liu TY, Chi CW. Male predominance in hepatocellular carcinoma: New insight and a possible therapeutic alternative. Med Hypotheses 2000;55:348-50.

15. Kaneto H, Sasaki S, Yamamoto H, Itoh F, Toyota M, Suzuki H, et al. Detection of hypermethylation of the p16INK4A gene promoter in chronic hepatitis and cirrhosis associated with hepatitis B or $\mathrm{C}$ virus. Gut 2001;48:372-7.

16. Li X, Hui AM, Sun L, Hasegawa K, Torzilli G, Minagawa M, et al. p 16INK4A hypermethylation is associated with hepatitis virus infection, age, and gender in hepatocellular carcinoma. Clin Cancer Res 2004; 10:7484-9.

17. Jung JK, Arora P, Pagano JS, Jang KL. Expression of DNA methyltransferase 1 is activated by hepatitis $B$ virus $X$ protein via a regulatory circuit involving the p16INK4a-cyclin D1- CDK 4/6-pRb-E2F1 pathway. Cancer Res 2007;67:5771-8.

18. Ro"cken C, Carl-McGrath S. Pathology and pathogenesis of hepatocellular carcinoma. Dig Dis 2001;19:269-78.

19. Shen L, Ahuja N, Shen Y, Habib NA, Toyota M, Rashid A, et al. DNA methylation and environmental exposures in human hepatocellular carcinoma. J Natl Cancer Inst 2002;94:755-61.

20. Weihrauch M, Benicke M, Lehnert G, Wittekind C, Wrbitzky R, Tannapfel A. Frequent k- ras-2 mutations and p 16INK4A methylation in hepatocellular carcinomas in workers exposed to vinyl chloride. Br J Cancer 2001;84:982-9.

21. Kondo Y, Kanai Y, Sakamoto M, Mizokami M, Ueda R, Hirohashi S. Genetic instability and aberrant DNA methylation in chronic hepatitis and cirrhosis: A comprehensive study of loss of heterozygosity and microsatellite instability at 39 loci and DNA hypermethylation on $8 \mathrm{CpG}$ islands in microdissected specimens from patients with hepatocellular carcinoma. Hepatology 2000;32:970-9.

22. Kim JR, Kim SY, Kim MJ, Kim JH. Alterations of CDKN2 (MTS1/ p 16INK4A) gene in paraffin-embedded tumor tissues of human stomach, lung, cervix and liver cancers. Exp Mol Med 1998;30:109-14.

23. Roncalli M, Bianchi P, Bruni B, Laghi L, Destro A, Di Gioia S, et al. Methylation framework of cell cycle gene inhibitors in cirrhosis and associated hepatocellular carcinoma. Hepatology 2002;36:427-32.

24. Wong IH, Lo YM, Zhang J, Liew CT, Ng MH, Wong N, et al. Detection of aberrant $\mathrm{p} 16$ methylation in the plasma and serum of liver cancers patients. Cancer Res 1999;59:71-3.

25. Baylin SB, Herman JG. DNA hypermethylation in tumorigenesis: Epigenetics joins genetics. Trends Genet 2000; 16:168-74.

26. Wong IH, Johnson PJ, Lai PB, Lau WY, Lo YM. Tumor-derived epigenetic changes in the plasma and serum of liver cancer patients: Implications for cancer detection and monitoring. Ann N Y Acad Sci 2000;906: 102-5.

How to cite this article: El-Mougy FA, Youssef MM, Omran DA, Sharaf SA, El-Sayed HH, Rabie WA, et al. Aberrant p 16INK4A methylation: Relation to viral related chronic liver disease and hepatocellular carcinoma. South Asian J Cancer 2014;3:1-4.

Source of Support: Nil. Conflict of Interest: None declared. 